\title{
Thermal Properties of Carbon Nanotube (CNT) Reinforced Polyvinyl Alcohol (PVA) Composites
}

\author{
Monirul Hasan ${ }^{1}$, Sujan Kumar Das ${ }^{2, *}$, Jahid M. M. Islam ${ }^{3}$, Md. Abdul Gafur $^{4}$, \\ Enamul Hoque ${ }^{5}$, Mubarak A. Khan ${ }^{3}$ \\ ${ }^{1}$ Department of Electrical and Electronic Engineering, Bangladesh University of Business and \\ Technology (BUBT), Dhaka - 1216, Bangladesh \\ ${ }^{2}$ Department of Physics, University of Chittagong, Chittagong - 4331, Bangladesh \\ ${ }^{3}$ Institute of Radiation and Polymer Technology, Bangladesh Atomic Energy Commission, \\ Dhaka - 1000, Bangladesh \\ ${ }^{4}$ Pilot Plant and Process Development Centre, Bangladesh Council of Scientific and Industrial \\ Research, Dhaka, Bangladesh \\ ${ }^{5}$ Department of Physics, Jahangirnagar University, Savar, Dhaka - 1342, Bangladesh \\ *E-mail address: skdas@cu.ac.bd
}

\begin{abstract}
Homogeneous Polyvinyl alcohol (PVA)/Carbon nanotube (CNT) composite has been prepared by solution casting method using gum acacia as a surfactant. CNT content in the composite was varied from $5-10 \%$ by weight. The thermal properties of PVA/CNT composites were investigated by Thermo Gravimetric/Differential Thermal Analyzer (TG/DTA) and Thermo Mechanical Analyzer (TMA). TG/DTA results showed that higher thermal stability in higher percentage of CNT in the composites. The $10 \%$ CNT containing PVA composite exhibit highest onset of melting, glass transition point and offset of melting temperature and the recoded values are $330.4 \mathrm{~K}, 379 \mathrm{~K}$ and $421.3 \mathrm{~K}$ respectively. All of the result indicates that the developed PVA/CNT composite might be promising for use in solar cell application.
\end{abstract}

Keywords: CNT; PVA; composite; Thermal properties; Gum acacia

\section{INTRODUCTION}

Carbon is one of the most abundant elements existing in nature. For centuries diamond and graphite were considered to be the only two types of all carbon crystalline structure which naturally existed as allotropes. The discovery of C60 also known as Fullerene [1], had an impact which extended way beyond the confines of academic chemical physics and marked the beginning of a new era in carbon science [2,3]. This C60 molecule contains 60 carbon atoms arranged in a spherical way, as in a soccer ball [4].

Several years later, lijima of NEC laboratories in Japan, discovered carbon nanotubes which proved to be the most important fruit of this research. Great attention has been attracted to this fascinating material which possesses extraordinary mechanical, electrical and thermal properties. One thing to note is that the carbon nanotubes observed by Iijima in 1991 [5] 
contained at least two concentric graphitic layers, which means they were multi-walled carbon nanotubes (MWNTs). The synthesis of the first Single-Walled Carbon Nanotubes (SWNTs) was reported two years later in 1993. This proved to be an extremely important development, since SWNTs seem to have a seamless structure and possess the potential to be the ideal reinforcement filler for the next generation of high performance composites.

Over the last few years, several production technologies have been developed for CNT reinforced polymer composite processing. Qian et al. [6] have prepared and characterized $1 \%$ carbon nanotubes (CNTs) in polystyrene matrix. The increase of tensile strength by $42 \%$, indicates significant load transfer across the CNT/Polystyrene nanocomposite. Zhang et al. [7] prepared SWNT / PVA composite films with polyvinyl pyrrolidone (PVP) and sodium dodecyl sulfonate (SDS) to assist the dispersion of the nanotubes. Several authors also have studied the characteristics of CNT reinforced polymer composites in different conditions [8-14]. To best of our knowledge, no investigation has been done on PVA/CNT composite with gum acacia to assist the dispersion of the CNT. Therefore, in our present work, we attempt to study the thermal properties of CNT reinforced PVA composite by using Thermo Gravimetric/Differential Thermal Analyzer (TG/DTA) and Thermo Mechanical Analyzer (TMA).

\section{EXPERIMENTAL}

\section{1. Materials}

Arc-discharge single walled carbon nanotubes (SWNTs) were used in this work as reinforcing material. PVA was supplied by MERK, Germany as matrix material. Gum acacia collected from Bangladesh Jute Research Institute (BJRI), which is used as surfactant.

\section{2. Methods}

Gum acacia used as the surfactant to disperse SWNTs in distilled water and sonicated for 2 hours by Digital Ultrasonic Bath (UBT-580). PVA was dissolved in distilled water along with varying percentages of dispersed CNTs to prepare various formulations. Table 1 shows six types of such formulations.

Table 1. Composition of different nanocomposite formulations ( $\% \mathrm{wt})$.

\begin{tabular}{|c|c|c|c|c|}
\hline Sample & $\begin{array}{c}\text { PVA } \\
\mathbf{( g m )}\end{array}$ & $\begin{array}{c}\text { CNT } \\
\mathbf{( g m )}\end{array}$ & $\begin{array}{c}\text { Gum acacia } \\
\mathbf{( g m )}\end{array}$ & $\begin{array}{c}\text { Distilled } \\
\text { water }(\mathbf{m l})\end{array}$ \\
\hline Pure PVA (0 \% CNT) & 5 & 0.00 & 0.10 & 100 \\
\hline $5 \%$ CNT containing PVA/CNT film & 5 & 0.25 & 0.10 & 100 \\
\hline $7 \%$ CNT containing PVA/CNT film & 5 & 0.35 & 0.10 & 100 \\
\hline $8 \%$ CNT containing PVA/CNT film & 5 & 0.40 & 0.10 & 100 \\
\hline 9\% CNT containing PVA/CNT film & 5 & 0.45 & 0.10 & 100 \\
\hline $10 \%$ CNT containing PVA/CNT film & 5 & 0.50 & 0.10 & 100 \\
\hline
\end{tabular}

The formulated solutions were cast on silicon paper (release film) mounted on level glass plate. The solutions were kept at room temperature for about 48 hours. After formation 
of the films, they were peeled off and cut into a dimension of $50 \times 10 \mathrm{~mm}^{2}$. Average thickness of the films was 0.1 to $0.3 \mathrm{~mm}$.

\section{RESULTS AND DISCUSSION}

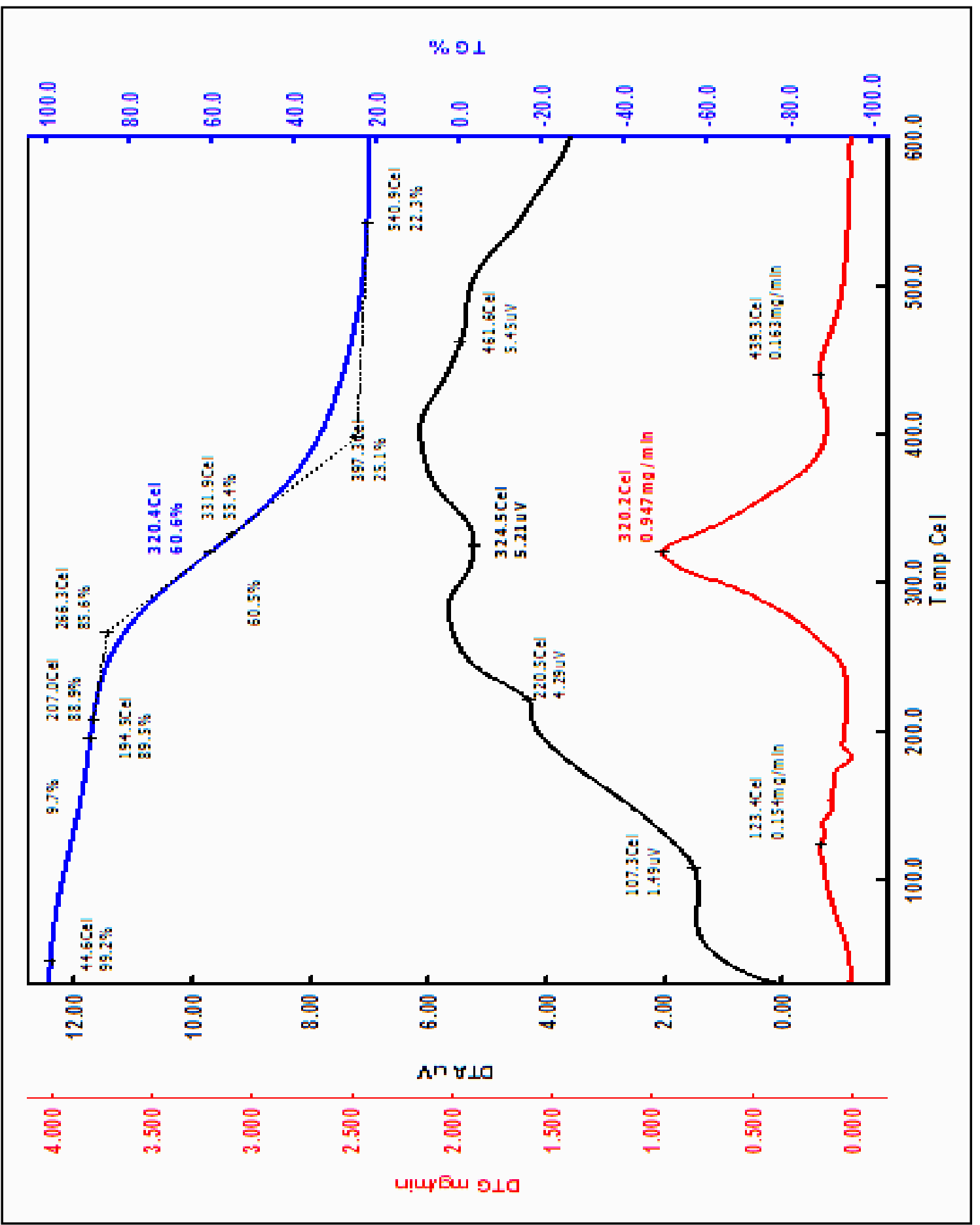

Fig. 1. TG, DTA and DTG for $0 \%$ CNT containing PVA nanocomposite. 


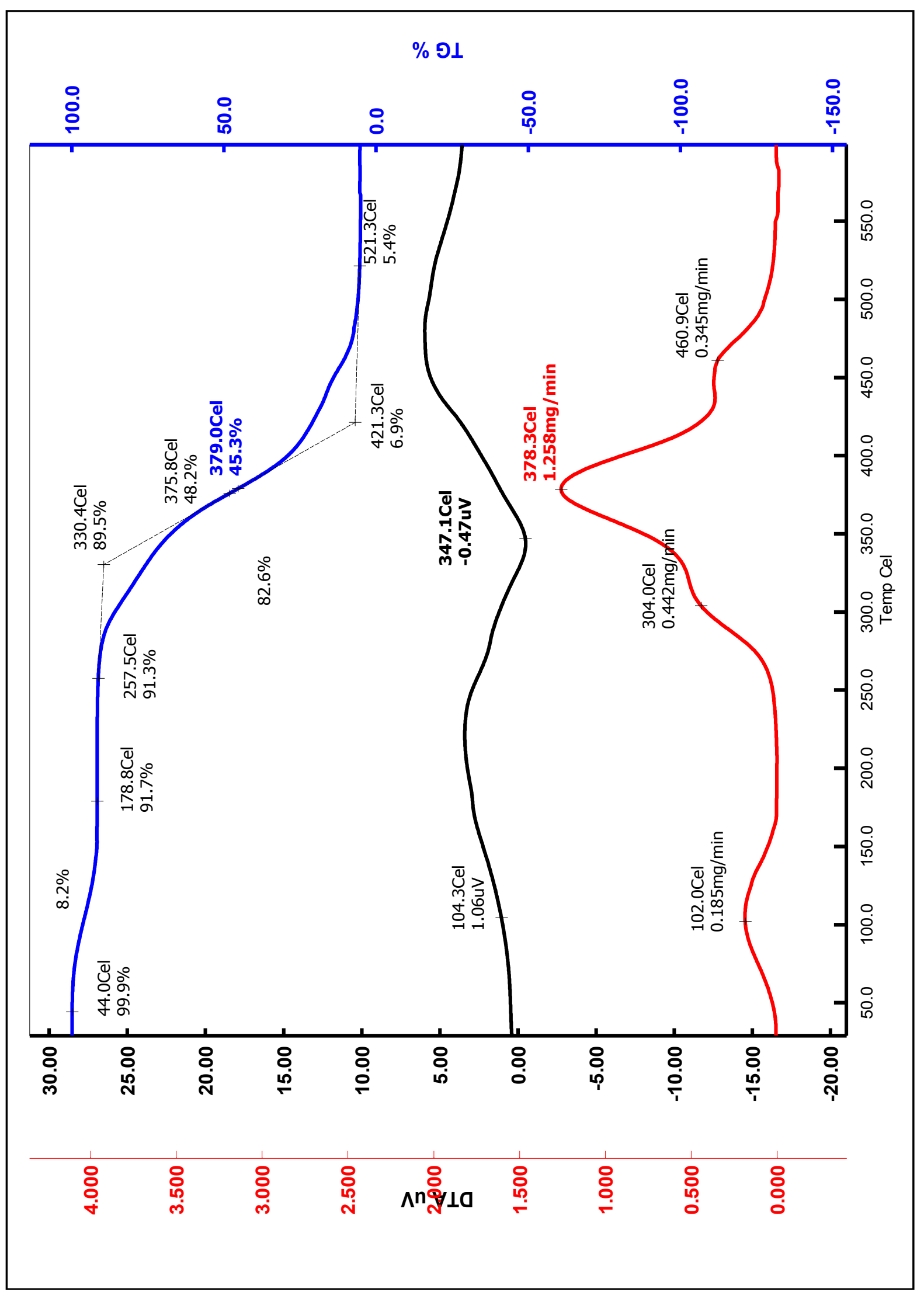

Fig. 2. TG, DTA and DTG for $10 \%$ CNT containing PVA nanocomposite. 
The thermal properties (Onset, offset of melting point and glass transition point) of the CNT reinforced PVA composites were evaluated using Thermo Gravimetric/Differential Thermal Analyzer (TG/DTA) and Thermo Mechanical Analyzer (TMA) under Nitrogen gas flow from $50{ }^{\circ} \mathrm{C}$ to $600{ }^{\circ} \mathrm{C}$. The TG, DTA, and DTG curves only for $0 \%$ and $10 \% \mathrm{CNT}$ containing PVA nanocomposite are given below (Fig. 1 and Fig. 2 respectively).

The Onset, offset of melting points and glass transition points of the pure PVA and the composites are given in Fig. 3. It has been found that the thermal properties of the composites improved significantly compared to pure PVA film.

The onset and offset of melting temperature for the pure PVA are found to be $266.5^{\circ} \mathrm{C}$ and $375.5{ }^{\circ} \mathrm{C}$ respectively. The $10 \%$ CNT reinforced PVA composite shows the highest onset and offset of melting temperature. It is clear from the bar diagram that the offset of melting point is increased up to $421.3{ }^{\circ} \mathrm{C}$ for $10 \%$ CNT reinforced PVA composite.

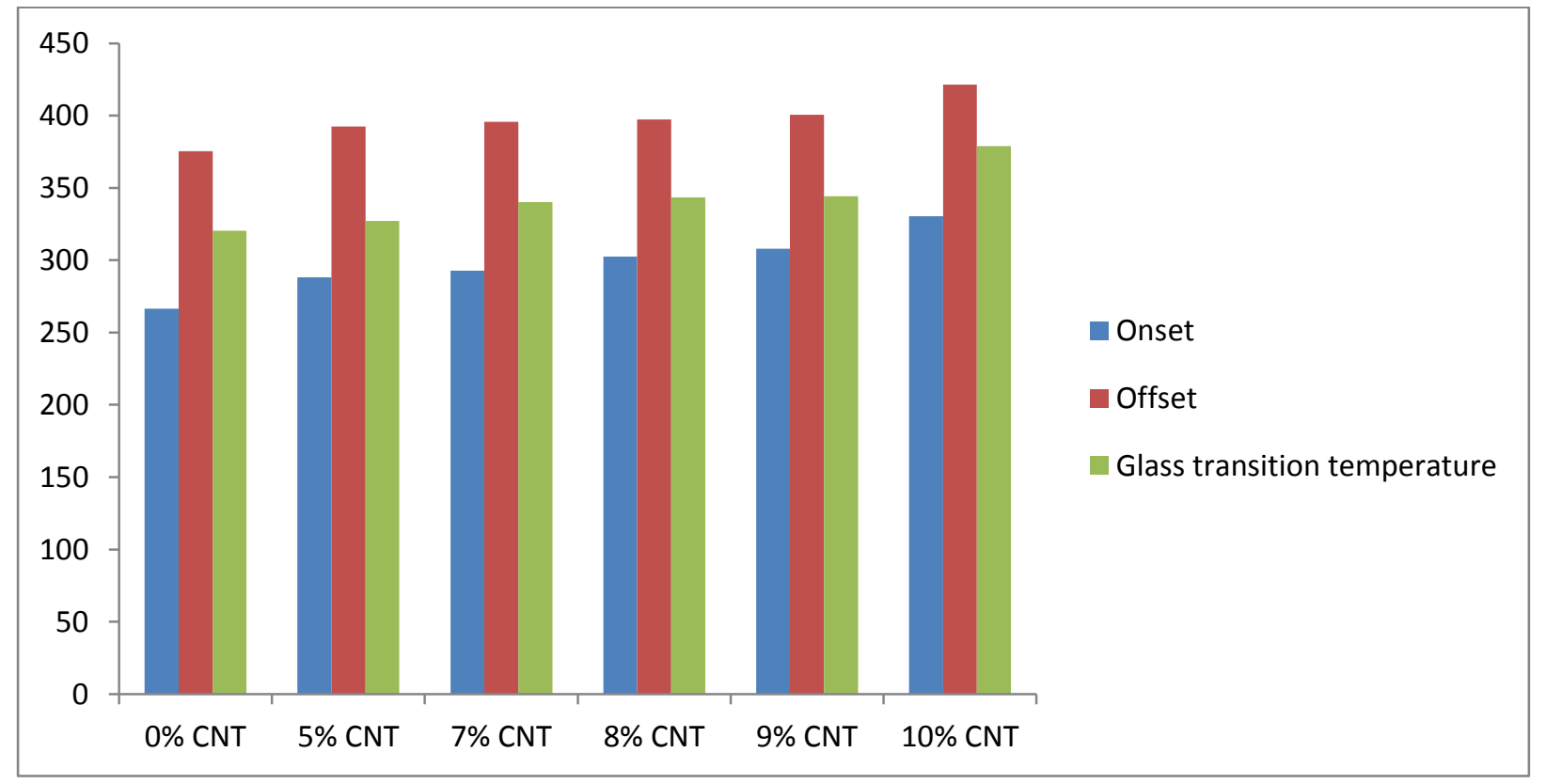

Fig. 3. Onset, offset of melting point and glass transition point temperatures for different $\% \mathrm{wt}$ of composition.

Table 2. Glass transition temperatures for different $\%$ wt of compositions.

\begin{tabular}{ccccccc}
\hline Compositions & $0 \%$ & $5 \%$ & $7 \%$ & $8 \%$ & $9 \%$ & $10 \%$ \\
\hline $\begin{array}{c}\text { Glass Trans. } \\
\text { Temp. }\left({ }^{\circ} \mathrm{C}\right)\end{array}$ & 320.4 & 327.2 & 340.2 & 343.3 & 344.3 & 379.0 \\
\hline
\end{tabular}

An important thermal property - glass transition point temperature for the pure PVA was found to be $320.4{ }^{\circ} \mathrm{C}$. The maximum glass transition point temperature was found for $10 \%$ CNT containing composite. The glass transition point temperature increases with the increase of $(\% \mathrm{wt})$ CNT composition. 


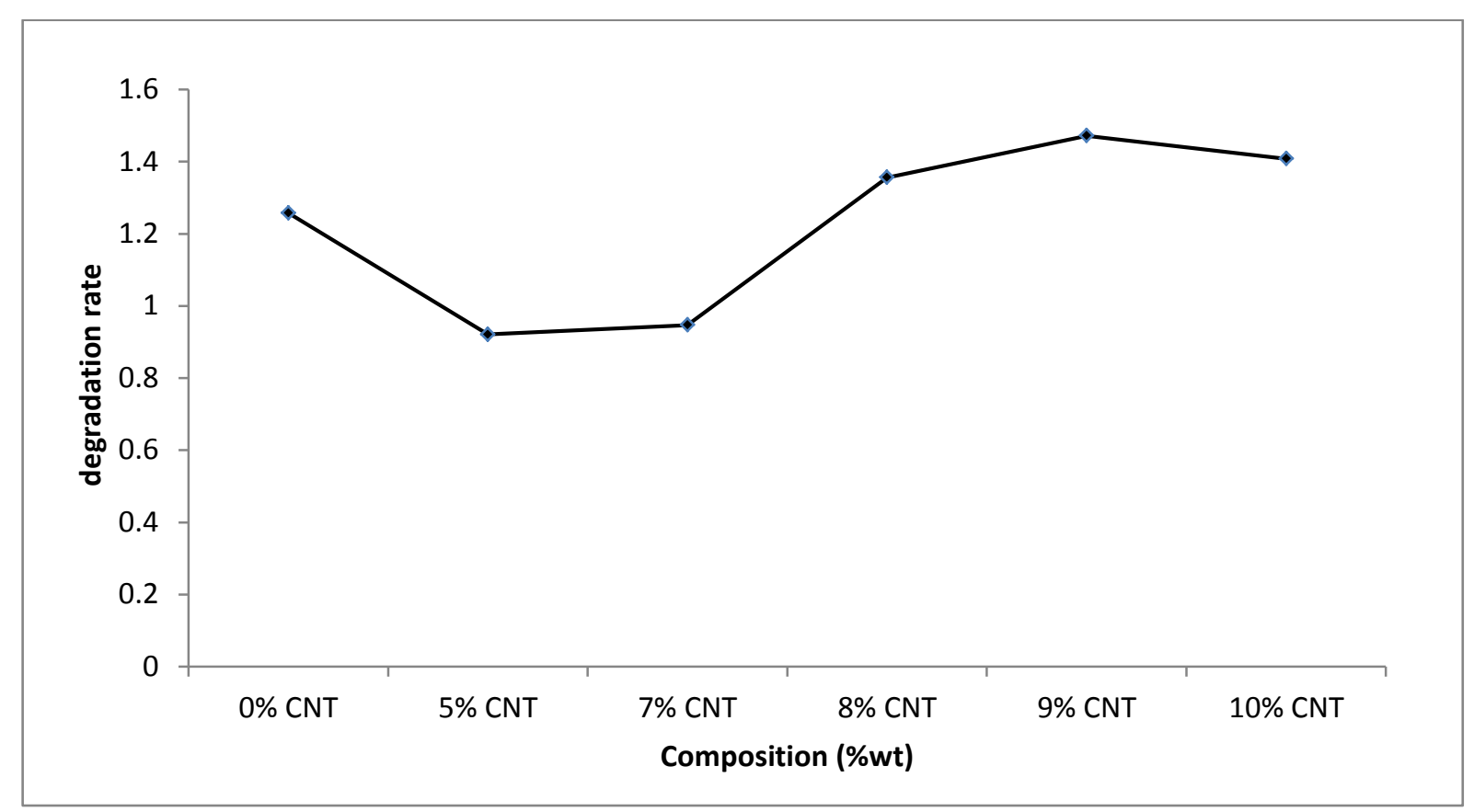

Fig. 4. Degradation rate for different $\%$ wt of composition.

Fig. 4 reveals that $9 \%$ CNT containing PVA composite shows the maximum degradation rate. The maximum degradation rate of $9 \%$ CNT containing PVA composite is $1.472 \mathrm{mg} / \mathrm{min}$ at $340.2 \mathrm{~K}$. The $5 \%$ CNT containing shows the lowest degradation rate at $327.2 \mathrm{~K}$. Pure PVA shows the degradation rate of $1.285 \mathrm{mg} / \mathrm{min}$.

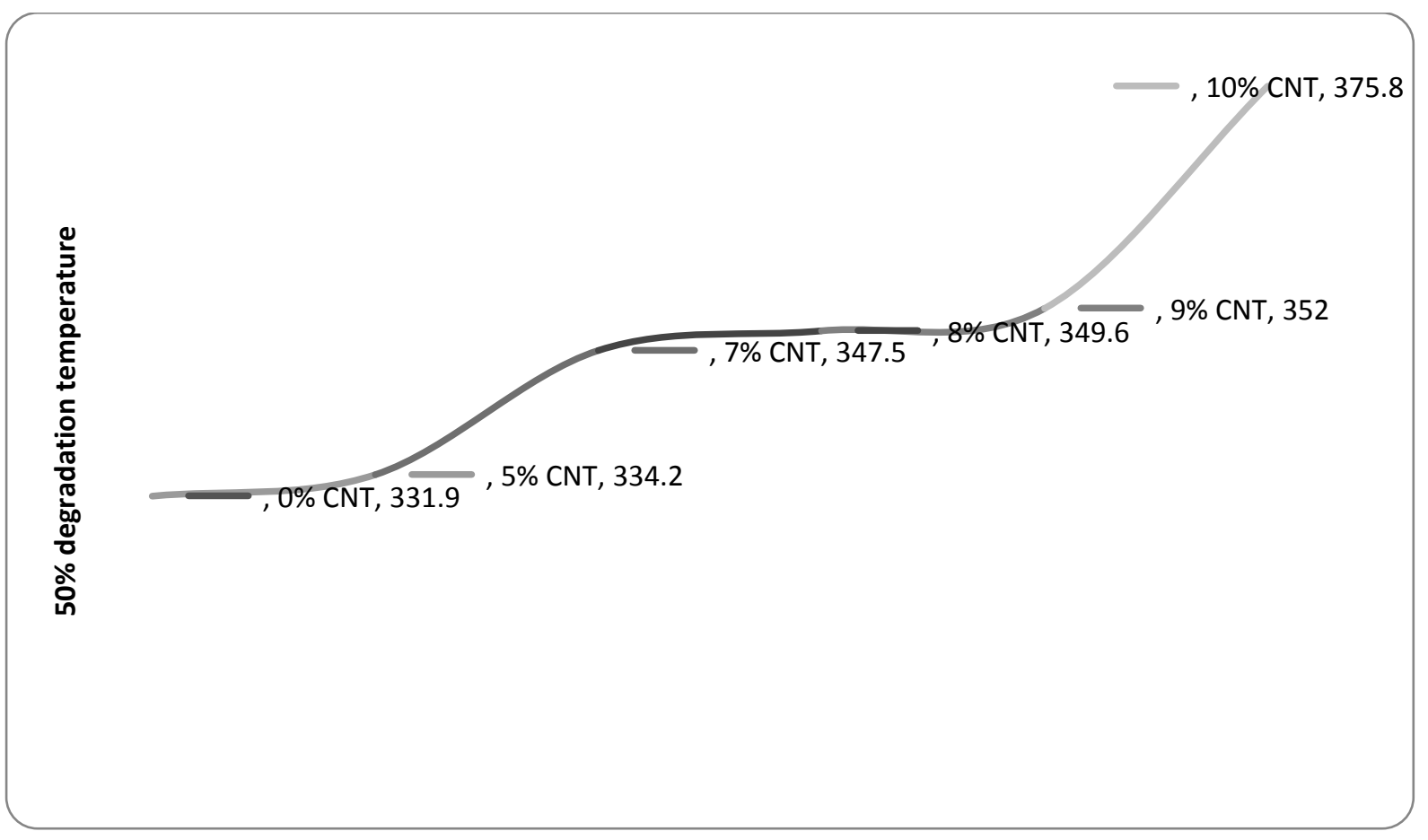

Fig. 5. $50 \%$ degradation temperature for different $\% \mathrm{wt}$ of composition. 
From Fig. 5 it is clear that $5 \%$ CNT containing composite has the lower $50 \%$ degradation and maximum slope temperature $(334.2 \mathrm{~K})$ than the other compositions. And 10 $\%$ CNT containing composite has the highest $50 \%$ degradation and maximum slope temperature $(375.8 \mathrm{~K})$. Fig. 5 also shows that pure PVA has the lowest highest $50 \%$ degradation and maximum slope temperature at $331.9 \mathrm{~K}$.

From this investigation it is clear that the thermal stability of the composites improved dramatically when CNT is incorporated into the matrix.

\section{CONCLUSION}

We have successfully modified the PVA composite by adding CNTs. It was found that, with respect to concentrations $10 \%$ CNT reinforced PVA composite showed the highest performance in thermal properties. The thermal properties have been drastically improved due to CNT content in the films. The glass transition temperature increases almost linearly due to increasing CNT content in the composite films. The present study also figured out the degradation study with temperature and revealed in which conditions the PVA/CNT composite degrade easily.

\section{Acknowledgement}

This research work was carried out in Institute of Radiation and Polymer Technology (IRPT) of Bangladesh Atomic Energy Research and Establishment (AERE), Department of Physics of Jahangirnagar University and Pilot Plant and Process Development Centre (PP \& PDC) of Bangladesh Council of Scientific and Industrial Research (BCSIR), Dhaka, Bangladesh.

\section{References}

[1] Kroto H. W., Rev. Mod. Phy. 69 (1991) 703.

http://www.des.upatras.gr/physics/christides/pdf\%5CKroto.pdf

[2] Ishida H., Campbell S., Blackwell J., Chem. Mater. 12 (2000) 1260-1267.

[3] Vaia R. A., Giannelis E. P., MRS Bulletin 26 (2001) 394-401. DOI: $10.1557 / \mathrm{mrs} 2001.93$

[4] Cumings John, Zettl A., Science 289 (2000) 602-604. http://mse.umd.edu/ cumings/PDF\%20Publications/02.Sci289cumings.pdf

[5] S. Iijima, Nature 354 (1991) 56-58. http://www.nature.com/physics/looking-back/iijima/iijima.pdf

[6] Qian D., Dickey E. C., Andrews R., Rantell T., Appl. Phys. Lett. 72 (1998) 188-190. http://dx.doi.org/10.1063/1.120680

[7] Zhang X., Liu T., Kumar, S., Moore V. C., Hauge R. H., Smalley R. E., Nano Letters 03 (2003) $1285-1288$.

DOI: $10.1021 / \mathrm{n} 1034336 \mathrm{t}$ 
[8] Chen XL, Liu YJ, Computational Materials Science 29 (2004) 1-11. http://dx.doi.org/10.1016/S0927-0256(03)00090-9

[9] Iijima S., Ichlhashi T., Nature 363 (1993) 603-605. doi: $10.1038 / 363603 \mathrm{a} 0$

[10] C. A. Cooper, S. R. Cohen, A. H. Barber, Appl. Phys. Lett. 81 (2002) 3873-3875.

[11] Wagner H. D., Chem. Phys. Lett. 361(2002) 57-61. DOI: $10.1016 / \mathrm{S} 0009-2614(02) 00948-\mathrm{X}$

[12] Zaho Q., Nardali M.B., Bernholc J., Phys. Rev. B 65 (2002) 144105. DOI:10.1103/PhysRevB.65.144105

[13] Shaffer M. S. P., Windle A. H., Advan. Mater. 11 (1999) 937-941. DOI: 10.1002/(SICI)1521-4095(199908)11:11<937::AID-ADMA937>3.0.CO;2-9

[14] Lourie O., Wagner H. D., Appl. Phys. Lett. 73 (1998) 3527-3529. http://dx.doi.org/10.1063/1.122825 